\title{
Method for measuring locomotive diesels characteristics for environmental monitoring tasks
}

\author{
Andrey Chernov ${ }^{1, *}$, Dmitry Chupiy ${ }^{1}$, and Maria Butakova ${ }^{1}$ \\ ${ }^{1}$ Rostov State Transport University, Information Technologies of Management Department, 344038 Narodnogo Opolchenya, 2, \\ Russia
}

\begin{abstract}
A method for measuring diesel engines characteristics based on recording the irregularities of time parameters of the crankshaft rotation is proposed. We demonstrate that the change of diesel engines characteristics significantly affects the established norms and limit values of engine emissions of pollutants and harmful substances. The ways of improving the environmental characteristics of diesel engines, including change of fuel composition by adding mixtures are considered. A method of control of the diesel engine parameters consisting in measuring the instantaneous values of the speed of the crankshaft rotation and assessing the deviations of these parameters from normal values has been proposed. The method is implemented in the form of procedures including data collection from sensors installed on the engine, data filtering, and their characteristic analysis. An autonomous measuring device based on the microcontroller has been developed with the help of which data has been collected from the sensors of the 16-cylinder turbocharged engine. We have carried out experiments on process data that determine possibly faulty engine elements that worsen its environmental parameters.
\end{abstract}

\section{Introduction}

The adoption of environmental standards and norms for maximum permissible pollution is a worldwide trend for the design and operation of modern internal combustion engines. Such engines including diesel engines of railway locomotives should be developed taking into account the possibility of environmental parameters control and requirements for polluting emissions [1]. Meanwhile, the railway network of our country already operates more than 10 thousand diesel engines as a part of locomotives, diesel trains, railbuses and other types of traction and motor-car rolling stock as well as dieselgenerator power stations. This technique was developed several decades ago but is still being operated and needs to be equipped with environmental monitoring systems.

New standards and methods for determining emissions of harmful substances and exhaust smoking of the traction rolling stock have been introduced since July 2017 by the new interstate standard GOST 33754-2016 "Emissions of harmful substances and exhaust smoking of autonomous traction and multiple-unit rolling stock. Norms and methods of definition". In particular, in the specified standard for perspective engines planned to be produced after 2020 is established that maximum admissible values of average emissions of harmful substances and exhaust gases on sums of nitrogen oxides $\left(\mathrm{NO}_{\mathrm{x}}\right)$, carbon $(\mathrm{CO})$ and hydrocarbons $(\mathrm{CH})$ are reduced more than by 3 times.
Reducing impacts of diesel engines on the environment and human health as well as dependence on traditional fossil fuels is primarily connected with the research in the field of development of biodiesels [2] and renewable and clean types of fuel. In our opinion, the most perspective promising directions of designing new types of diesel engines are the directions of development of biodiesels with alternative fuel technologies, for example, diesel mixtures containing rapeseed oil [3]. The expected results connected with an increase in the percentage of alternative fuel in the conventional diesel fuel are a decrease of exhaust gas temperature and a reduction of hydrocarbons, nitrogen oxide and carbon monoxide emissions on an average of up to $30 \%$ for B75 - B100 biodiesels. Another approach to the improvement of the environmental characteristics of the rolling stock diesel engines is to improve fuel quality by adding mixtures containing nanoparticles. In this particular case, it is possible to distinguish fuel mixtures for biodiesels with the addition of molybdenum trioxide [4], alumina hydroxide [5], composite $30 \mathrm{ppm}$ nanoparticles Alumina $\left(\mathrm{Al}_{2} \mathrm{O}_{3}\right)$ and Cerium oxide $\left(\mathrm{CeO}_{2}\right)$ [6]. The addition of graphene oxide GO nanoparticles to the fuel [7] is very encouraging for improving the environmental cleanliness of diesel engines that shows a reduction in emissions of $\mathrm{NO}_{x}$ by $45 \%$, CO by $55 \%$, and $\mathrm{CH}$ by $50 \%$ for a conventional diesel engine.

Another direction of improving the environmental characteristics of diesel engines is the development of

\footnotetext{
* Corresponding author: a.v.chernov@hotmail.com
} 
diesel-hydrogen engines [8]. However, when some limit concentrations of hydrogen are reached, on the contrary, the effects of a significant deterioration in the productivity and environmental friendliness of diesels can be observed [9].In addition, vibration characteristics and exhaust gases of engines and biodiesels are very important environmental issues in this field [10].

For powerful diesel engines the following operational parameters are usually regulated: total service life, repair intervals, current maintenance, and overhaul repairs. A serviceable and tuned engine has normalized and predictable parameters of exhaust gases [11], and in the course of normal operation of the serviceable engine, the composition of the exhaust gas mixture does not significantly change [12], [13]. A significant increase of harmful impurities appears in the process of change of fuel characteristics [14], wear of engine parts, contamination of fuel equipment, as well as improper maintenance and operation. This significantly worsens the efficiency of fuel combustion that leads to the appearance of a large number of harmful substances in the exhaust gases as well as reduces the overall efficiency of the engine [15].

Technologies based on intelligent systems, in particular, artificial neural networks are widespread methods of modeling, optimizing environmental parameters and improving the efficiency of diesel engines [16]. Such technologies are used not only for conventional diesel engines but can also be applied to biodiesels [17] and engines running on liquefied gas [18]. Forecasting of parameters and optimization of harmful substances emissions by engines can be carried out on the basis of hybrid artificial neural networks and genetic algorithms [19], wavelet neural networks [20], and laser absorbing spectroscopy [21].

In repair intervals, it is necessary to carry out periodic inspections of the condition and operating parameters of engines. In terms of environmental parameters control either a direct analysis of the gas mixture on the exhaust or an analysis of the basic operating parameters of the engine is usually carried out. In case of their significant deviation from the norm, the analysis of the gas mixture is done. In the existing environmental monitoring devices, the assessment of the diesel engine is based on information collected from various sensors: pressure and temperature of the incoming air, exhaust gases, turbocharger delivery pressure, load, coolant temperature, engine speed in different modes. However, the conclusion about the environmental condition of the engine has integrated and averaged character throughout the unit.

In the next section of the article, it will be shown that a much greater amount of useful information suitable for environmental monitoring tasks can be obtained by assessing the nature of the engine crankshaft movement. The nature of the uneven movement of the engine crankshaft reflects the processes occurring in each of the combustion chambers. If the engine has a fault that relates to a particular cylinder, it is possible to detect it by measuring a set of environmental parameters.

\section{Methods}

We have proposed and implemented a control method of the main parameters of the diesel engine consisting of measuring the instantaneous values of the crankshaft rotation speed and assessing the deviations of these parameters from normal values. The implementation of this method required rapid measurement of small-time intervals with fine precision and high dynamic range. Practical implementation became possible on the basis of high-performance autonomous computing devices, microcontrollers with ARM architecture with high-speed peripherals. This made it possible to perform a circuit solution in the form of the compact autonomous information and measurement module.

Let us consider our developed method in more detail.

At the first stage, the diesel engine is equipped with Hall sensor and GMR digital gear tooth sensor without interfering into the main structure, as it is shown in Fig.1. Hall sensor (1) in Fig.1 is used to obtain information about the speed of the crankshaft movement and is installed next to the driven gear of the starter drive so that the surface of the gear teeth during the rotation passes close to the non-magnetic sensor gap. Highprecision sensor Infineon TLI4963-2M defining the magnetic field present in the range from $-2 . .6 \mathrm{mT}$ at the temperature of diesel up to $125^{\circ}$ was used for our construction.

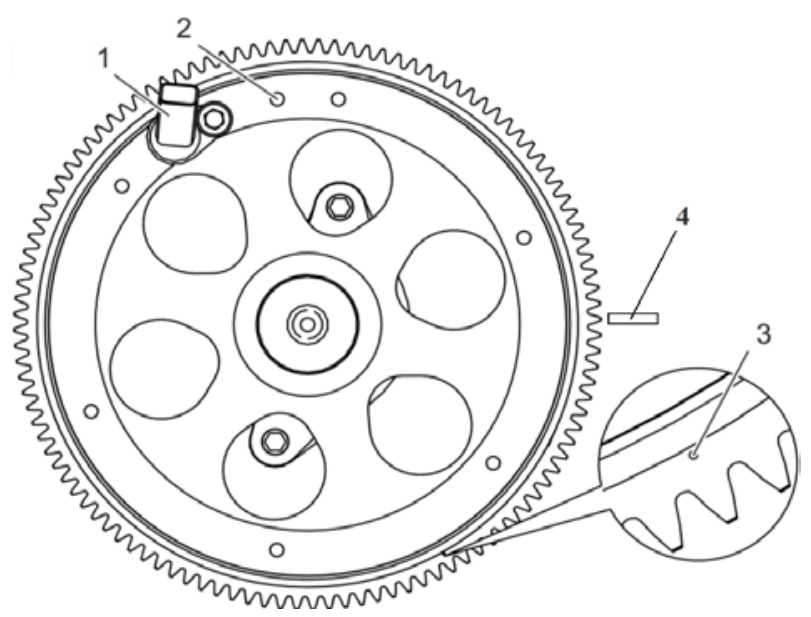

Fig. 1. Installation of sensors on the diesel crankshaft gear: 1 - Hall sensor Infineon TLI4963-2M; 2 - synchronous mark; 3 - installing mark; 4 - GMR digital gear tooth sensor NVE AKL001-12E.

The diesel crankshaft gear is made of steel and thus it has a high magnetic permeability, passing the tooth surface near the sensor causes a pulse change in the current at the output of the sensor (4) in Fig.1. The NVE AKL001-12E sensor was used in our construction, output signals of which were digital pulses that encoded the number of gear teeth passed through it. The connection diagram of both sensors is shown in Fig. 2.

Digital voltage impulses from the Hall sensor Infineon TLI4963-2M are fed to the microcontroller input, which registers and stores them. The sequence of current impulses from GMR digital gear tooth sensor NVE AKL001-12E is fed to the comparator that is 
performed on the operational amplifier OAmp and then to the microcontroller which measures the time intervals between impulses. The gear of the engine has 124 teeth, and the operating cycle of the engine is repeated every 2 revolutions, and thus 248-time intervals are obtained.

The measuring construction was installed on 1A$5 \mathrm{~d} 49$ diesel engines. This is 16-cylinders turbocharged locomotive diesel engine and an analog of the one from General Electric 7FDL-16/7HDL-16 diesel engine series.

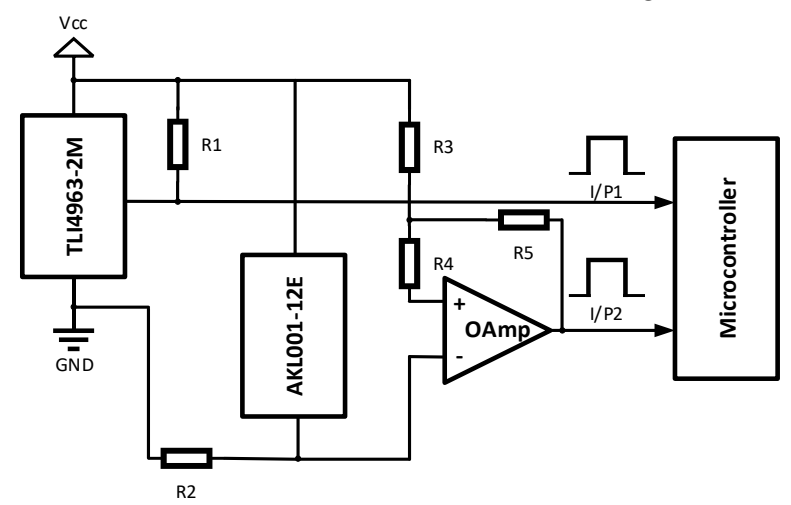

Fig. 2. Connection diagram of sensors to the microcontroller.

At the second stage, the time intervals of the crankshaft gear teeth passing near GMR digital gear tooth sensor NVE AKL001-12E and the frequency of the diesel engine rotation are registered by Hall sensor Infineon TLI4963-2M. The example of raw data obtained during bench tests of the 16-cylinder engine 1A-5D49 of the 2TE116 diesel locomotive in the repair depot is shown in Fig. 3.

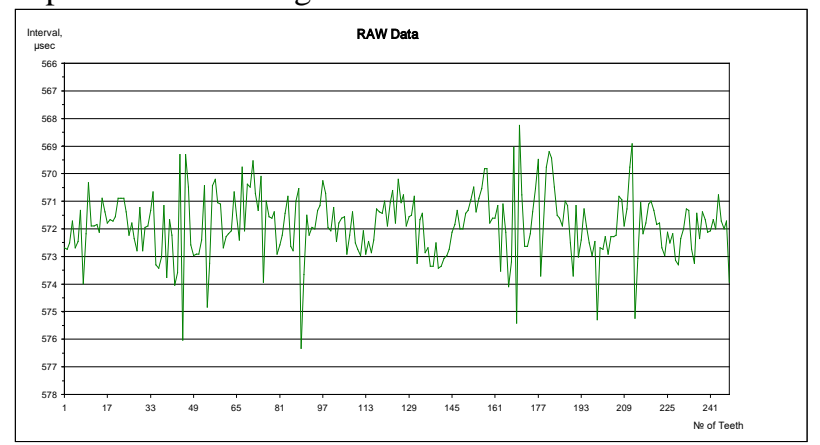

Fig. 3. A sample of the time intervals raw data from turbocharged locomotive 2TE116 diesel engine 1A-5D49.

The initial data are obtained directly from the sensor for 2 engine revolutions, 248 measurements, at a speed of crankshaft rotation of $500 \mathrm{rpm}$. From Fig. 3 it is obvious that there is a significant irregularity of time intervals of recording the passage of the crankshaft gear teeth that indicates the unevenness of cylinders operation due to wear of parts or changes in fuel composition. These circumstances change environmental parameters of the engine which can be improved by various settings.

At the third stage filtering procedures of the received data from noise values are carried out. The useful information is selected based on the software implementation of a finite impulse response filter (FIRfilter). The main advantage of FIR-filters was used in our method which is to provide the required amplitudefrequency response of the filter over the entire dynamic range of measurements as well as the linearity and predictability of the phase shift it introduces that can be easily compensated if necessary. In practical calculations, we used the following filtering algorithms, block diagrams of which are presented in Fig. 4 and Fig. 5. As is known the FIR-filter impulse response can be set arbitrarily and is formed by coefficients array [22]. In our case the filtration coefficients were calculated with the use of the normalized sinc (sinus cardinalis) function

$$
h(t)=\sin (\pi f 0 t) /(\pi f 0 t)=\sin (15 \pi t) /(6.7 \pi t)
$$

In equation (1) the filter the bandwidth $f_{0}=15 \mathrm{~Hz}$ has been used.

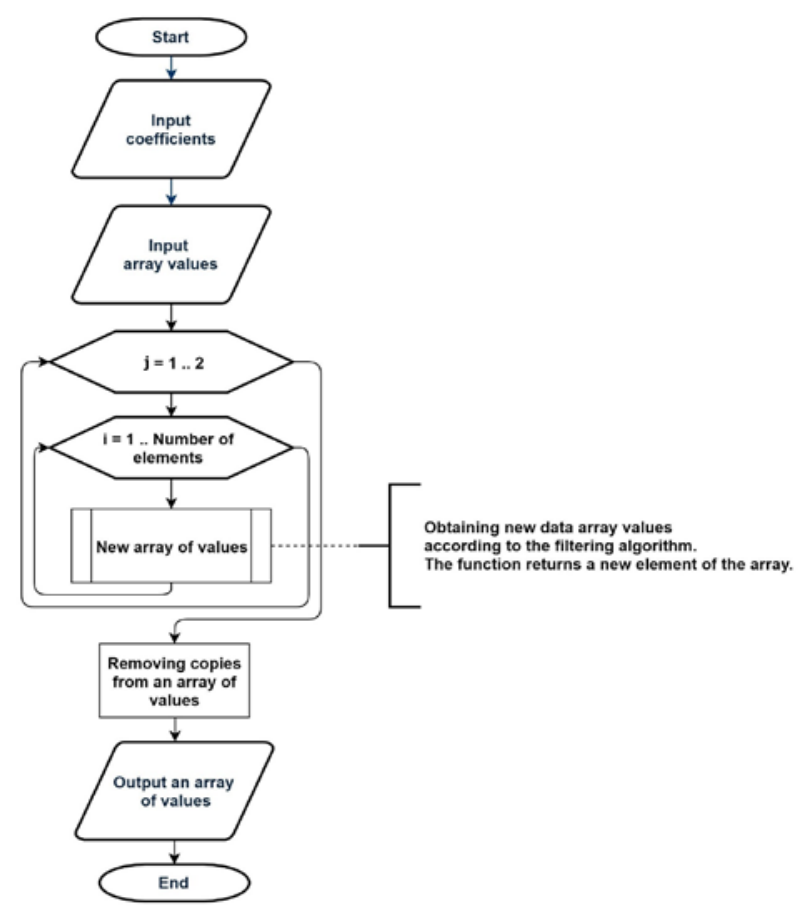

Fig. 4. Block diagram of FIR-filter coefficient calculation algorithm.

At the fourth stage, the data are displayed on the characteristic deployment diagram $720^{\circ}$, which clearly shows the processes occurring in each of the combustion chambers of the diesel engine. Fig. 6 shows the example of the characteristic diagram constructed on raw data (raw data), where each of the 16 sectors designated 1A$8 \mathrm{~A}, 1 \mathrm{~B}-8 \mathrm{~B}$ contains time intervals for recording the passage of the crankshaft gear teeth near the GMR digital gear tooth sensor NVE AKL001-12E. 


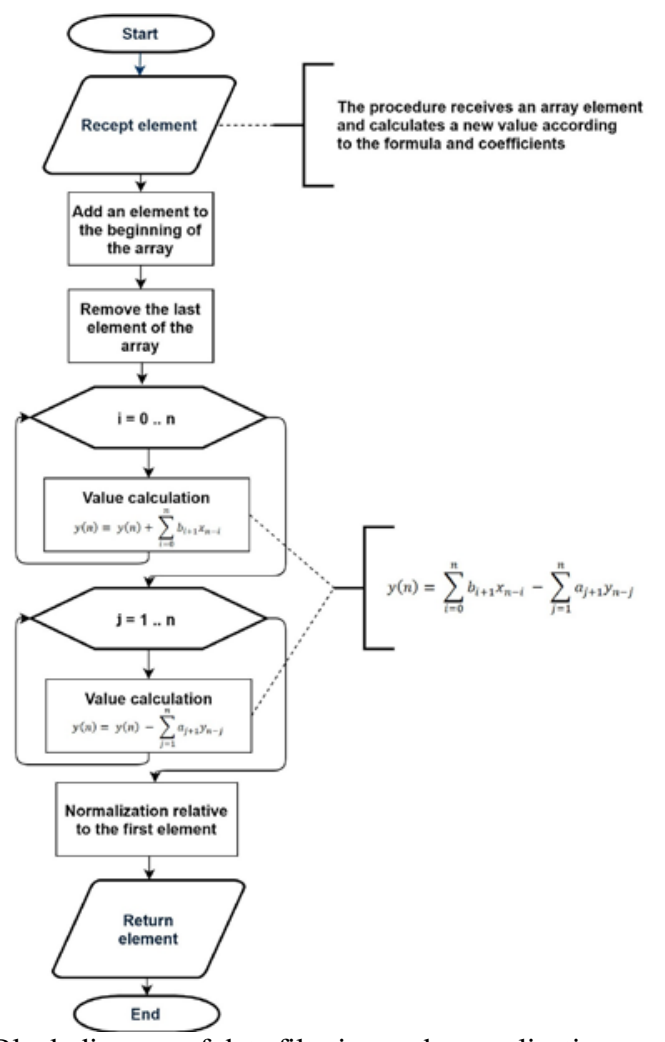

Fig. 5. Block diagram of data filtering and normalization algorithm.

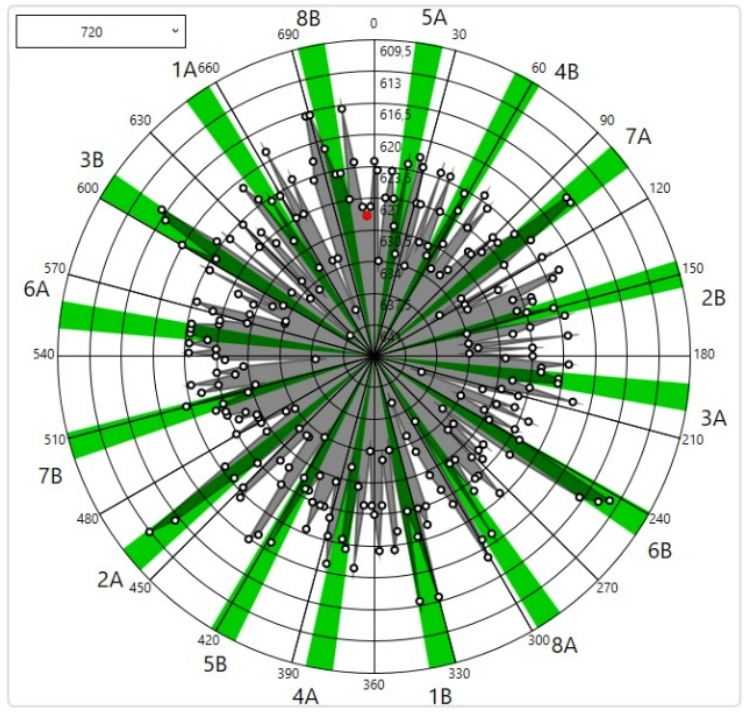

Fig. 6. Characteristic diagram of processes in combustion chambers of 16-cylinder turbocharged diesel engine 1A-5D49.

After filtering the input values at the final stage, an expert evaluation of the obtained characteristic diagram is made by comparing it with a reference or idealized diagram of a serviceable diesel engine.

\section{Results and discussion}

The authors of the article have practically implemented a programmable device for problems of environmental monitoring of diesel engines. The device whose appearance is shown in Fig. 7 uses two 32-bit ARMCortexM3 microcontrollers of STM32F103 architecture as computing modules. The 16-cylinder turbo diesel engine 1A-5D49 of diesel locomotive 2E116 was selected for tests. The engine was equipped with pulse sensors collecting the information about the speed of the crankshaft rotation, the speeds of shafts rotation of the valve timing system as well as their initial positions. For registration, the general condition of the engine and correct comparison under the conditions of specific measurements the developed device registers additional information from sensors of speed rotation of the engine camshaft, temperature and fuel consumption, pressure and air temperature in a turbo-charger, pressure in cylinders.

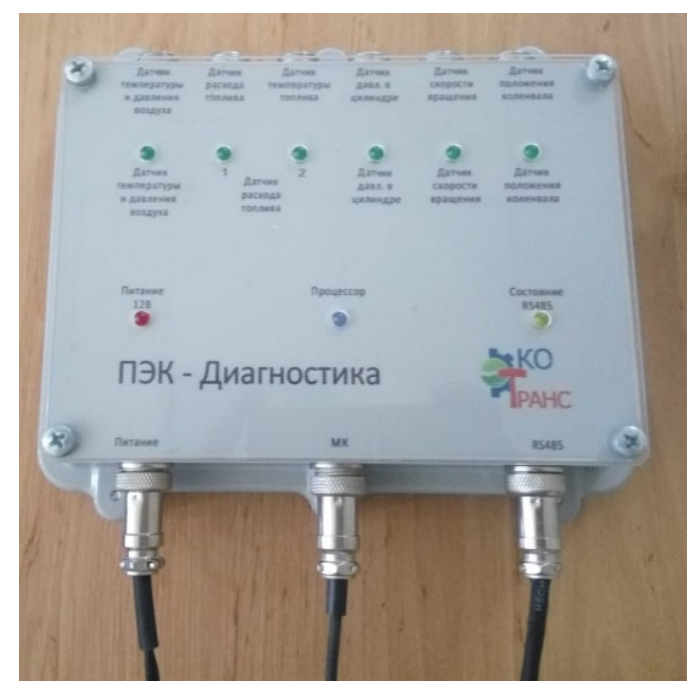

Fig. 7. Physical form and design of the device.

Next, we will illustrate the application of the proposed method. To obtain useful information several different data processing algorithms received from the sensor have been tested including a mode of data averaging with different window widths. Next Fig. 8 and Fig. 9 present respectively the results of data processing by averaging method on 8 and 16 neighboring values. 


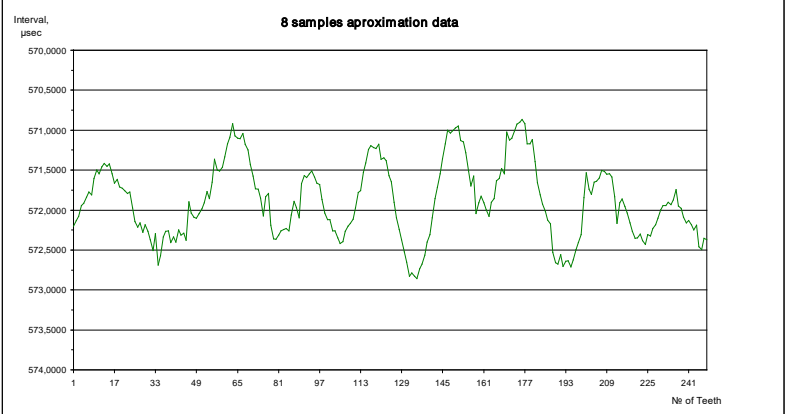

Fig. 8. 8 samples approximation of data after filtering.

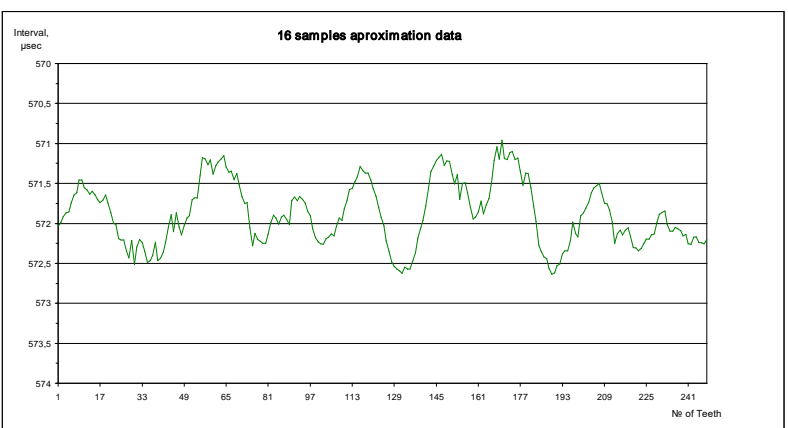

Fig. 9. 16 samples approximation of data after filtering.

Further increase in the size of the filtering window does not significantly improve the degree of filtering. A significant improvement in filtering results was achieved by the sequential inclusion of filter elements, by applying a 2nd order filter to average 8 adjacent input data elements. The result is shown in Fig. 10.

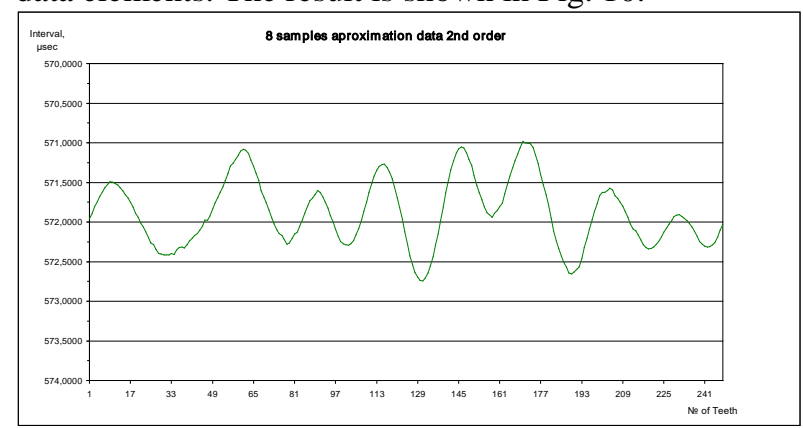

Fig. 10. 8 samples approximation of data after $2^{\text {nd }}$ order filtering

The final filtering method, which is applied in our device, consists in feeding to the filter input values averaged by two neighboring elements, and then in the procedure of secondary filtering of the values obtained at the filter first stage output. After filtering, the obtained result is presented in the characteristic diagram shown in Fig. 11.

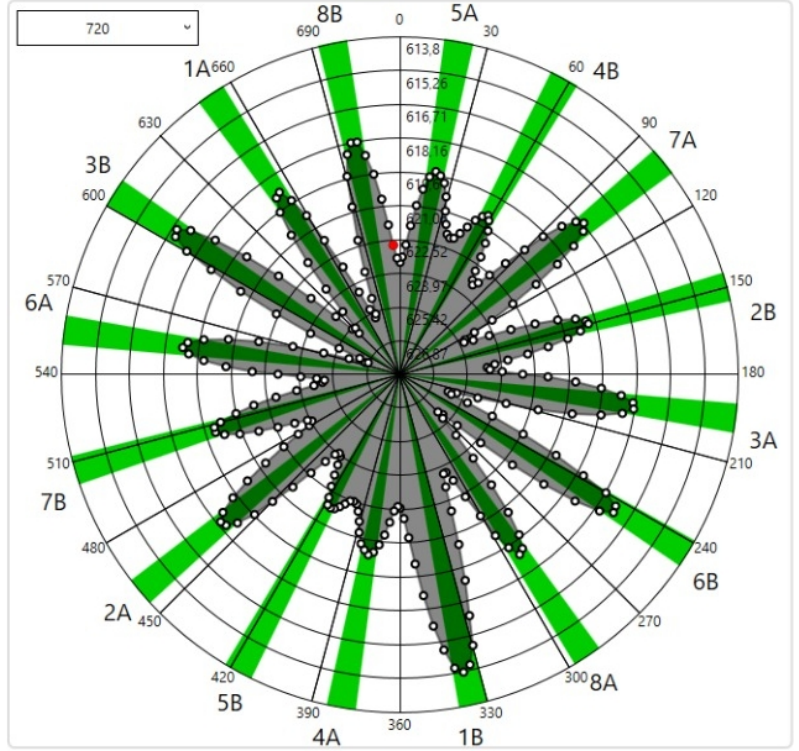

Fig. 11. Characteristic diagram of processes in combustion chambers of 16-cylinder 1A-5D49 turbocharged diesel engine after data filtering.

The diagram clearly shows all operational phases of the engine's all combustion chambers. Taking this into account it is possible to draw a conclusion about the changed environmental parameters of the engine due to deterioration of cylinders $4 \mathrm{~B}$ and $5 \mathrm{~B}$ performance. The authors have developed an original low-cost method of environmental monitoring of diesel engines. The method uses procedures of data collecting, filtering and analyzing of speed and irregularity of diesel engine crankshaft rotation. As a consequence of the uneven operation of the engine, there is a change in its environmental parameters. This method makes it possible to evaluate not only the environmental parameters of diesel engines but assess and compare the processes occurring in each combustion chamber as well. In addition, it is possible to determine and classify the instability of engines performance that in many cases allows preventing the development of a serious malfunction by performing timely maintenance or repair.

\section{Acknowledgements}

The work was carried out with the financial support of the RFFR, project 18-08-00549-a.

\section{References}

1. M. Puškár, M. Kopas, and J. Kádárová, Transp. Res. Part D Transp. Environ. 57, 413 (2017)

2. Y. H. Taufiq-Yap, M. S. Ahmad Farabi, O. N. Syazwani, M. L. Ibrahim, and T. S. Marliza, in Appl. Therm. Eng. 162, 114259 (2019)

3. L. A. Raman, B. Deepanraj, S. Rajakumar, and V. Sivasubramanian, Fuel 246, 69 (2019)

4. D. Mei, L. Zuo, D. Adu-Mensah, X. Li, and Y. Yuan, Appl. Therm. Eng. 162, 114238 (2019) 
5. M. Srinivasa Rao and R. B. Anand, Appl. Therm. Eng. 98, 636 (2016)

6. A. Prabu, Ain Shams Eng. J. 9, 2343 (2018)

7. A. I. EL-Seesy and H. Hassan, Renew. Energy 132, 558 (2019)

8. T. Natriashvili, R. Kavtaradze, and M. Glonti, IOP Conf. Ser. Mater. Sci. Eng. 315, 012018 (2018)

9. H. Koten, Int. J. Hydrogen Energy 43, 10511 (2018)

10. V. Velmurugan, S. M. Aathif Akmal, V. Paramasivam, and S. Thanikaikarasan, Mater. Today Proc. (2019)

11. M. Mofijur, N. M. S. Hassan, and M. N. Uddin, Energy Procedia 160, 791 (2019)

12. J. Pullen and K. Saeed, Energy 72, 1 (2014)

13. J. Pullen and K. Saeed, Energy 72, 17 (2014)

14. P. TAN, J. ZHAO, Z. HU, D. LOU, A. DU, and D. DU, J. Fuel Chem. Technol. 41, 347 (2013)

15. E. Arcaklioğlu and İ. Çelıkten, Appl. Energy 80, 11 (2005)

16. W. K. Yap, T. Ho, and V. Karri, Int. J. Hydrogen Energy 37, 8704 (2012)

17. K. Prasada Rao, T. Victor Babu, G. Anuradha, and B. V. Appa Rao, Egypt. J. Pet. 26, 593 (2017)

18. T. F. Yusaf, D. R. Buttsworth, K. H. Saleh, and B. F. Yousif, Appl. Energy 87, 1661 (2010)

19. H. Taghavifar, S. Khalilarya, and S. Jafarmadar, Energy 71, 656 (2014)

20. R. Rahimi molkdaragh, S. Jafarmadar, S. Khalilaria, and H. Soukht Saraee, Energy 142, 1128 (2018)

21. Z. Wang, X. Liu, Y. Mu, X. Yang, L. Yang, and Z. Jiang, Optik (Stuttg). 164, 126 (2018)

22. M. Parker and M. Parker, Digit. Signal Process. 101 41 (2017) 